\title{
TOMOGRAPHY OF CALCIFIED AORTIC AND MITRAL VALVES
}

\author{
BY \\ PAGET DAVIES AND N. L. BUCKY \\ From King's College Hospital \\ Received May 29, 1958
}

The purpose of this paper is to compare the value of fluoroscopy and tomography in distinguishing aortic from mitral valve calcification. In view of this difficulty, certain criteria are recorded to aid their identification.

Aortic valve calcification was first described in 1672 by Rayger (quoted by Bonetus, 1679). Eighty-two years later, Morgagni recorded a patient dying in cardiac failure who had a bony aortic valve. Single patients with both aortic and mitral valve calcification at necropsy were reported by Turner (1885) and Weber (1898). But not until the last twenty-five years have reports of aortic valve calcification been common and only since then has the condition been recognized in life (Christian, 1931; Sparks and Evans, 1934; Blackford et al., 1936; Berk and Dinnerstein, 1938). In 1933, Sosman and Wosika described the fluoroscopic recognition of mitral and aortic valve calcification. Further reports by Sosman appeared in 1939 and 1943.

Tomography was first applied to the detection of aortic valve calcification by Davies and Steiner (1949) who recorded fourteen such patients: they found it to be more successful than fluoroscopy. Daley (1957), however, stated that fluoroscopy was more reliable than tomography for showing aortic valve calcification, but thought that the image intensifier was best. Simon (1956) thought that in centres where the image intensifier was not available, there was still a place for tomography of the heart valves.

With the advent of valvotomy, the detection of calcification became important because its presence was soon found to affect the outlook for success. Both Baker et al. (1952) and Wood (1954) found that gross calcification of the mitral valve, especially when associated with mitral regurgitation, made a successful valvotomy unlikely. Even if regurgitation is not initially present, valvotomy may lead to this when the valve is calcified (Wood, 1954). Although Turner and Fraser (1956) agreed that calcification may make valvotomy difficult or even impossible, they found good results in more than half their patients. They confirmed Wynn's findings that heavy calcification of the mitral valve altered the mitral rhythm of Duroziez (1862) and thought fluoroscopy better than tomography for showing calcification.

Campbell and Kauntze (1953) thought that calcification was nearly always present in congenital aortic stenosis after forty years of age and favoured stenosis of the valve rather than the subaortic region. Brock agreed (1957a) and thought it important that when there is calcification its site should be determined and recorded permanently (1957b).

\section{Methods AND MATERIAL}

Tomography was performed on all patients as follows : 6,8 , and $10 \mathrm{~cm}$. cuts from the anterior chest wall were taken using $64 \mathrm{KV}$ and $64 \mathrm{MAS}$ with the patient in the left anterior oblique position at $10^{\circ}$ rotation; and 3 and $5 \mathrm{~cm}$. cuts from the spine were taken using $70 \mathrm{KV}$ and $80 \mathrm{MAS}$ with the patient in the left lateral position.

Sixteen patients with aortic, and twelve with mitral valve calcification were examined personally. Four others with aortic and three with mitral calcification on tomography were added to the series making a total of thirty-five. 
Significant mitral regurgitation was diagnosed in the presence of mitral stenosis according to the following criteria: (1) a mitral holosystolic murmur with clinical and radiographic evidence of an enlarged left ventricle in the absence of aortic valve disease and hypertension, (2) a short apical diastolic murmur, and (3) electrocardiographic evidence of left ventricular preponderance.

Using fluoroscopy, we thought that the most helpful distinguishing point of valve calcification was its dancing movement. Generally in postero-anterior views the aortic valve was mid-line in position while the mitral valve was lower and to the left of the mid-line. In lateral views, we found, as did Davies and Steiner (1949), that while the aortic valve usually is anterior to the mitral valve, they may be on the same vertical plane. Gross cardiomegaly (Sosman and Wosika, 1933) may cause considerable shifting of the valves. We found it difficult to distinguish calcification in the posterior cusp of the aortic valve from that in the anterior mitral leaflet, as did Sosman and Wosika (1934). On tomography we thought that the form of the calcification was most useful in distinguishing each valve. Thus aortic valve calcification showed as a channel or ring in fourteen patients (Davies and Steiner, 1949) (Fig. 1). In contrast, mitral valve calcification usually is like
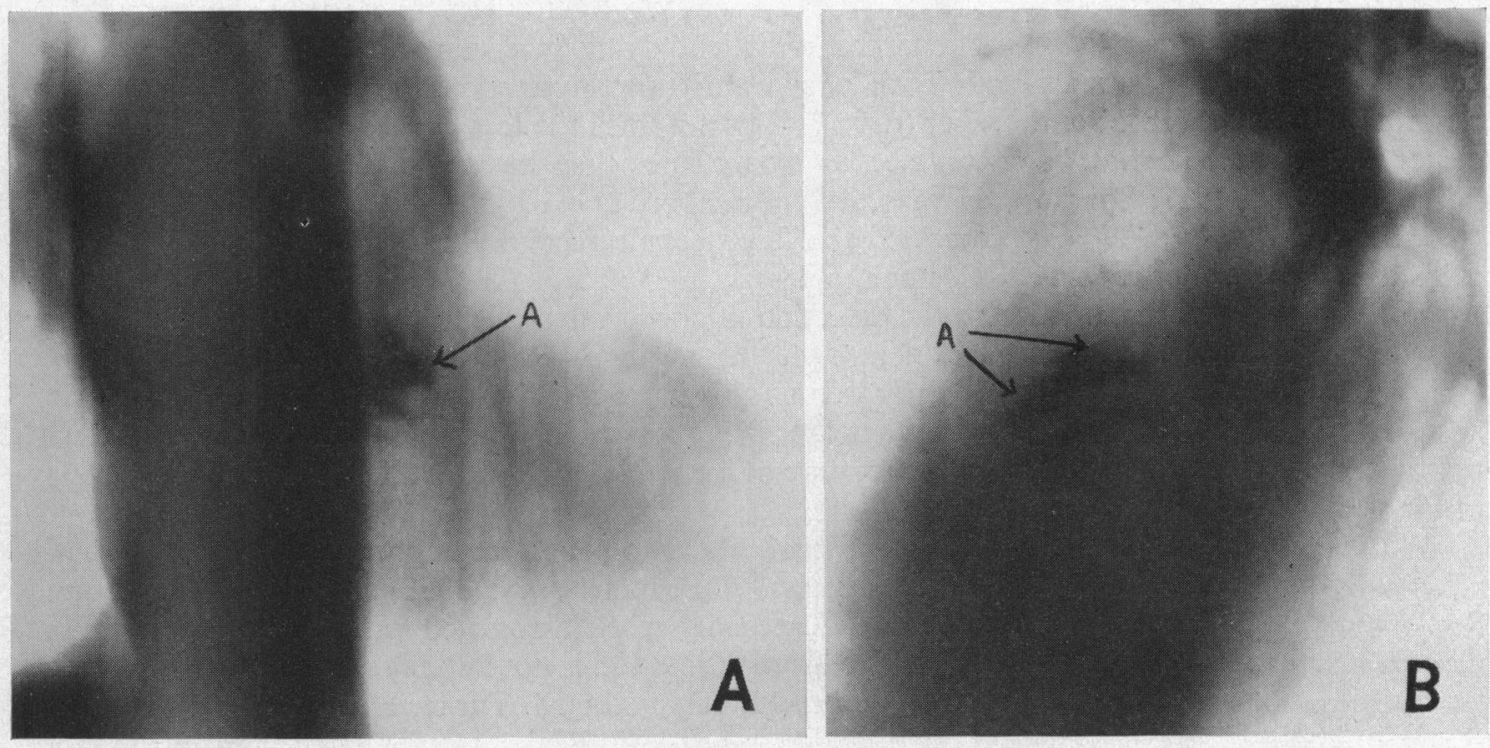

FIG. 1.-(A) Oblique tomogram, showing aortic valve calcification (A) as a channel just to the left of the mid-line. (B) Lateral tomogram, showing aortic valve calcification (A) as a ring in the middle third of the heart shadow.

an irregular star or band (Fig. 2). Using barium paste in the valves of a cadaver, we were able to confirm these findings (Fig. 3). In addition to showing the typical distribution of calcium, another advantage of tomography over fluoroscopy is that it provides a permanent record of valve calcification which may be studied at leisure, so reducing observer error.

During this investigation, two other patients were seen with gross syphilitic aortic regurgitation. In both the calcified dilated aorta showed clearly the origin of the aorta and hence the site of the aortic valve (Fig. 4). 

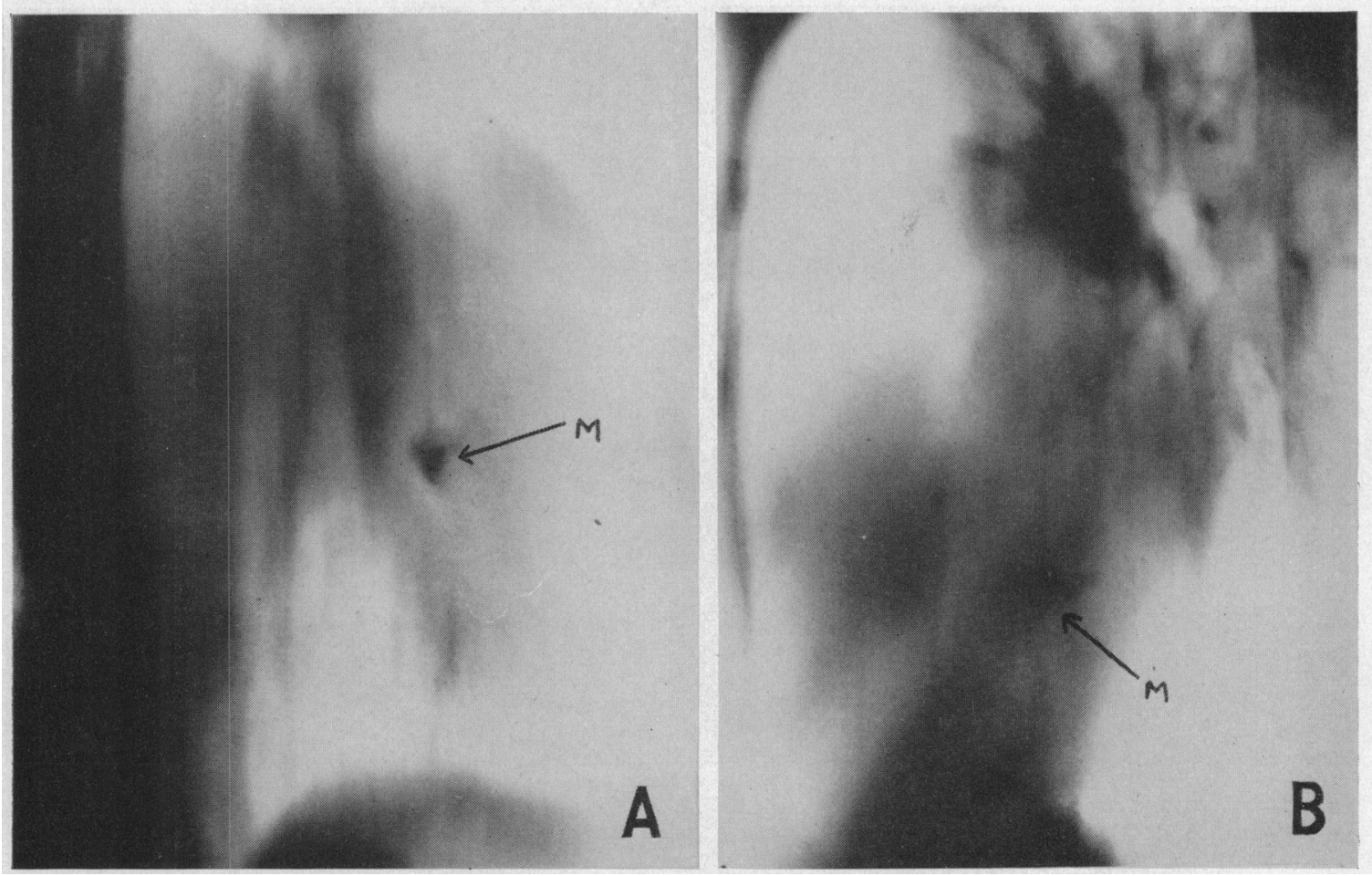

FIG. 2.-(A) Oblique tomogram, showing mitral valve calcification (M) as an irregular star well to the left of the midline. (B) Lateral tomogram, showing mitral valve calcification (M) as an irregular band in the posterior third of the heart shadow. The aortic valve lies at a higher level than the mitral (compare Fig. 1).

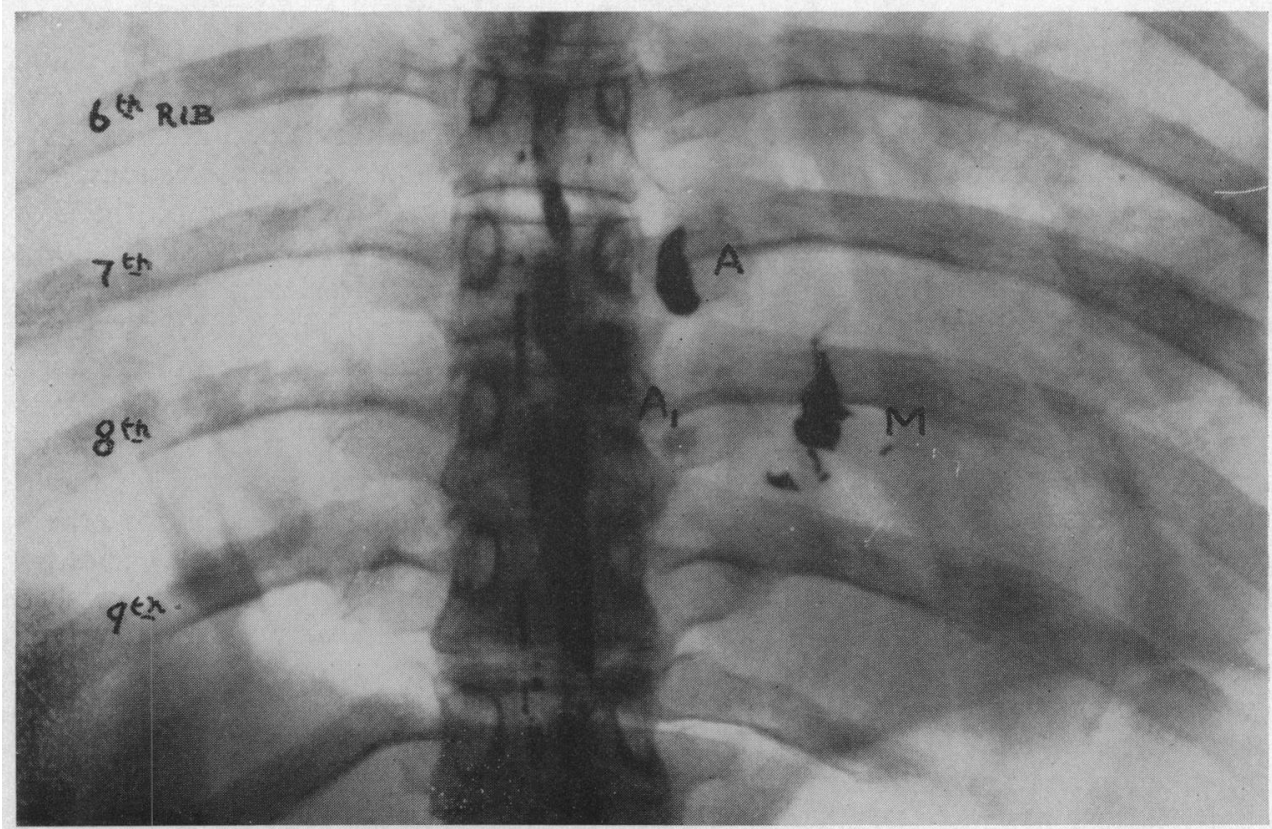

FIG. 3.-Antero-posterior chest radiograph, showing site of aortic $\left(\mathrm{AA}_{1}\right)$ and mitral $(\mathrm{M})$ valves (outlined with barium paste in the cadaver). The mid-line shadows are due to a previous myelogram. 


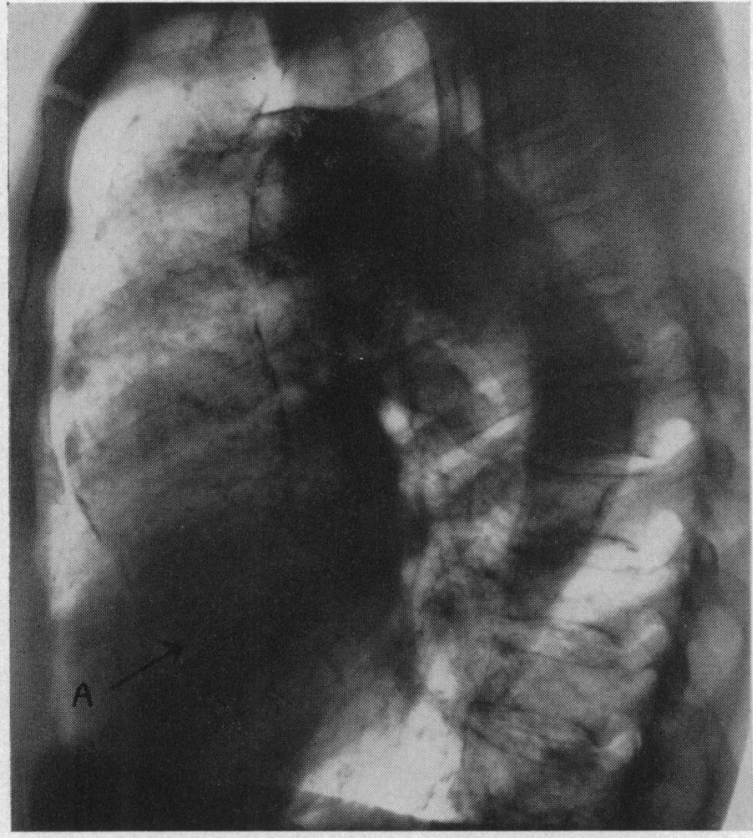

FIG. 4.-Lateral chest radiograph in syphilitic aortitis. The calcified dilated aorta shows clearly the origin of the aorta and hence the site of the aortic valve (A).

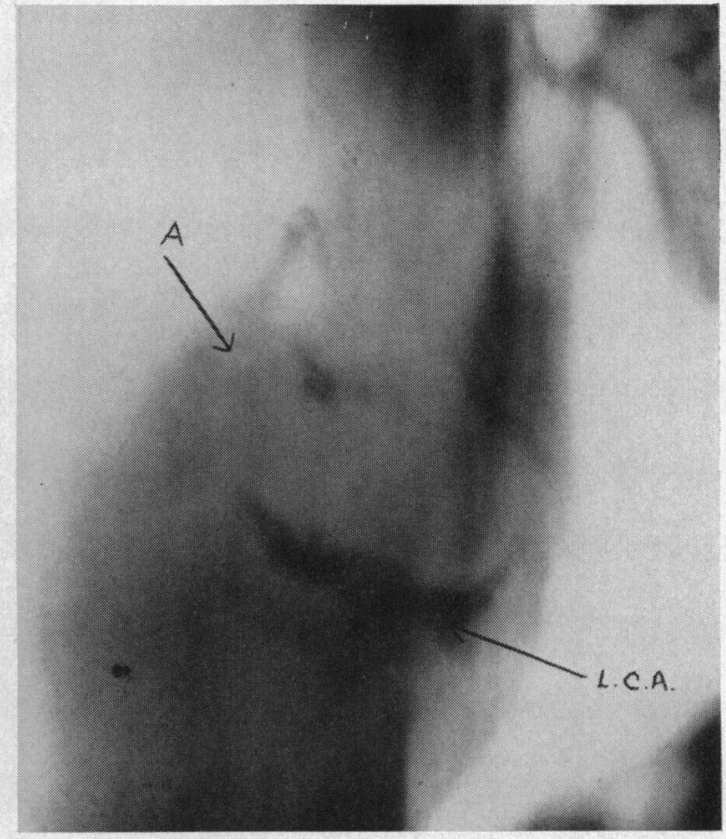

FIG. 5.-Lateral tomogram, showing calcific aortic stenosis (A) and calcified anterior descending branch of the left coronary artery (L.C.A.).

\section{DisCUSSION}

Following Sosman and Wosika's careful technique (1933) many workers have used fluoroscopy to demonstrate calcified aortic and mitral valves (Sparks and Evans, 1934; Bishop and Roesler, 1934; Blackford et al., 1936; Berk and Dinnerstein, 1938; Epstein, 1940; Wood, 1948; Kiloh, 1950; Campbell and Kauntze, 1953; and Wynn, 1953). Despite such technique, detection of aortic and mitral valve calcification when one or both be present may be difficult and at times impossible. Indeed reference to necropsy material shows that such calcification may be contiguous.

In the patients described, calcification was recorded with certainty by tomography in 33 out of 35 patients and probably in the other two. Of this number, 19 had aortic valve calcification seen on tomography, whereas fluoroscopy failed to show any evidence of calcification in two, shared doubtful calcification in one, and left its site uncertain in one: the other four were not examined. Two patients of this group subsequently underwent valvotomy and calcification of the aortic valve was confirmed in both.

Of the fourteen patients with certain, and one with doubtful, calcification of the mitral valve on tomography eleven later had a valvotomy: in all, calcification was present. Of these eleven, fluoroscopy was unsuccessful in showing calcification in three, and also so in one other patient who did not have an operation. One patient, the youngest in the series ( 23 years), is of particular interest. Mitral valvotomy at another hospital had been unsuccessful, because of a grossly calcified valve, but at a second valvotomy a reasonable split was obtained with a Tubb's valvulotome: calcification was found on the medial aspect of the valve.

We were able to confirm Wynn's observation (1953) that calcification of the mitral valve does not affect the mitral diastolic murmur (Table I). The first sound rarely seemed affected by calcification, being loud in ten patients, normal in two, and soft in three. In contrast the opening snap was absent in all but one of our patients. Similar findings were noted by Wynn (1953) and by Mounsey and Brigden (1954). In seven of our patients, pulmonary hypertension was present which may itself 
TABLE I

Influence of Calcification on Mitral Rhythm of Duroziez

\begin{tabular}{|c|c|c|c|c|c|}
\hline $\begin{array}{l}\text { Number of } \\
\text { patients }\end{array}$ & $\begin{array}{c}\text { Mitral } \\
\text { first } \\
\text { sound }\end{array}$ & $\begin{array}{l}\text { Systolic } \\
\text { murmur }\end{array}$ & $\begin{array}{l}\text { Mitral } \\
\text { opening } \\
\text { snap }\end{array}$ & $\begin{array}{c}\text { Diastolic } \\
\text { murmur }\end{array}$ & $\underset{\text { rhythm }}{\text { Duroziez }}$ \\
\hline \multirow{3}{*}{15} & 10 loud & \multirow{2}{*}{9 present* } & \multirow{2}{*}{1 present } & \multirow{2}{*}{15 present } & \multirow{2}{*}{1 present } \\
\hline & 2 normal & & & & \\
\hline & 3 soft & 6 absent & 14 absent $\dagger$ & - absent & 14 absent \\
\hline
\end{tabular}

* 4 had significant mitral regurgitation.

$\dagger 7$ had pulmonary hypertension.

cause the opening snap to disappear. A mitral systolic murmur was heard in nine patients, of whom four had significant mitral regurgitation and a calcified mitral valve. Duroziez's mitral rhythm of a presystolic reinforcement, split second sound with or without opening snap, rumbling diastolic murmur, and no systolic murmur, which he likened to ffout-ta-ta-roû . . . was heard in only one patient. Potain (1894) although he does not mention calcification remarked that with a rigid valve the Duroziez rhythm disappeared.

There were five patients in the series with severe combined aortic and mitral valve disease. One had mitral valve calcification only, both on fluoroscopy and tomography. In two, tomography showed only aortic valve calcification. In one of these calcification was thought to be in the mitral valve on fluoroscopy, and a calcified left coronary artery was noted on tomography and fluoroscopy; and in the other the site of the calcification seen on fluoroscopy was uncertain. One patient with severe aortic and mitral valve calcification at operation and necropsy had previously had this demonstrated on tomography. One other has so far come to necropsy and contiguous calcification was present in both valves: on fluoroscopy only aortic valve calcification was seen and doubtfully so on tomography. Thus the combination of mitral valve calcification and calcific aortic stenosis was found in two patients only, of whom one had a history of rheumatism. One other patient with calcific aortic stenosis and complete heart block is of interest, since East (1932), Boas (1935), and Windholz and Grayson (1947) attributed this to invasion of the conducting system by calcification (Fig. 5): in addition the anterior descending branch of the left coronary artery was calcified suggesting also a possible ischæmic cause for the arrhythmia. Pyke and Symonds (1951), however, in their review of cardiac calcification found that none of their patients with calcified coronary arteries had clinical or cardiographic evidence of heart disease.

\section{Summary AND CONCLUSIONS}

The history and significance of radiological demonstration of calcified aortic and mitral valves are reviewed. Twenty patients with calcification of the aortic valve and fifteen with calcification of the mitral valve are described.

Tomography is more reliable than fluoroscopy, since calcification is detected more frequently and the site is located with more certainty. It will show which valve is affected from the form and position of the calcification. Finally, tomography has the advantage of providing a permanent record.

The influence of mitral calcification on the mitral rhythm of Duroziez, on the regurgitation through the valve, and on valvotomy is discussed. Mitral valve calcification in association with calcific aortic stenosis is rare, and was seen in only two of the thirty-five patients.

We are grateful to Dr. Samuel Oram and Dr. J. Blewett for initiating this study and their constant encouragement and advice; and Dr. Clifford Hoyle for reading the manuscript. We wish to thank the physicians and surgeons of King's College Hospital who have allowed us to study their patients. 


\section{REFERENCES}

Baker, C., Brock, R. C., Campbell, M., and Wood, P. (1952). Brit. med. J., 1, 1043.

Berk, L. H., and Dinnerstein, M. (1938). Arch. intern. Med., 61, 781.

Bishop, P. A., and Roesler, H. (1934). Amer. J. Roentgenol., 31, 1.

Blackford, L. M., Bryon, W. W., and Hollar, E. D. (1936). J. Amer. med. Ass., 107, 18.

Boas, E. P. (1935). Amer. J. med. Sci., 190, 376.

Bonetus, T. (1679). Sepulchretum sine anatomia practica ex cadaveribus morbo denatis. Geneva, 1679. Vol. 1, book 2. Observatio XXVI, p. 891 in the edition of 1700.

Brock, R. C. (1957a). Brit. med. J., 1, 1019 (1957b). Guy's Hosp. Rep., 106, 221.

Campbell, M., and Kauntze, R. (1953). Brit. Heart J., 15, 179.

Christian, H. A. (1931). J. Amer. med. Ass., 97, 158.

Daley, R. (1957). Proc. Roy. Soc. Med., 50, 817.

Davies, C. E., and Steiner, R. E. (1949). Brit. Heart J., 11, 126.

Duroziez, P. (1862). Arch. Gen. Med., 20, 385.

East, T. (1932). Proc. Assn. Phys., Quart.J. Med., 25, 693.

Epstein, B. S. (1940). Amer. J. Roentgenol., 44, 704.

Kiloh, G. A. (1950). Brit. Heart J., 12, 33.

Morgagni, J. B. (1761). Quoted from Willius, F. A. and Keys, T. A. (1941). Cardiac Classics. Kimpton, London. p. 183.

Mounsey, P. (1953). Brit. Heart J., 15, 135.

- and Brigden, W. (1954). Brit. Heart J., 16, 255.

Potain, C. (1894). Clinique medicale de la Charité, p. 184. Masson, Paris.

Pyke, D., and Symons, C. (1951). Brit. Heart J., 13, 355.

Simon, G. (1956). Principles of Chest X-ray Diagnosis, p. 157. Butterworth \& Co., London.

Sosman, M. C., and Wosika, P. H. (1933). Amer. J. Roentgenol., 30, 328.

-, (1939). Amer. Heart J., 10, 156. (1939). Amer. J. Roentgenol., 42, 47.

(1943). Amer. J. Roentgenol., 50, 461.

Sparks, J. V., and Evans, C. (1934). Brit. med. J., 1, 1028.

Turner, F. C. (1885). Trans. Path. Soc. London, 36, 144.

Turner, R. W. D., and Fraser, H. R. L. (1956). Lancet, 2, 525, 587.

Weber, F. P. (1898). Trans. Path. Soc. London, 49, 41.

Windholz, F., and Grayson, C. (1947). Amer. J. Roentgenol., 58, 411.

Wood, P. (1948). Modern Trends in Diagnostic Radiology, p. 161. Butterworth \& Co., London. (1954). Brit. med. J., 1, 1051, 1113.

Wynn, A. (1953). Brit. Heart J., 15, 214. 